\title{
Treatment with oligonol, a low-molecular polyphenol derived from lychee fruit, attenuates diabetes-induced hepatic damage through regulation of oxidative stress and lipid metabolism
}

\author{
Jeong Sook Noh, Chan Hum Park and Takako Yokozawa* \\ Institute of Natural Medicine, University of Toyama, 2630 Sugitani, Toyama 930-0194, Japan \\ (Received 30 July 2010 - Revised 13 January 2011 - Accepted 18 January 2011 - First published online 11 April 2011)
}

\begin{abstract}
We have identified the effects of oligonol, a low-molecular polyphenol derived from lychee fruit, on oxidative stress and lipid metabolism in a type 2 diabetic model. Oligonol was orally administered at 10 or $20 \mathrm{mg}$ per kg body weight per d for 8 weeks to $d b / d b$ mice, and its effects were compared with those of the vehicle in $d b / d b$ and $m / m$ mice. Serum and hepatic biochemical factors, and protein and mRNA expression related to lipid metabolism were measured. In the oligonol-administered group, there were significant reductions of reactive oxygen species (ROS), lipid peroxidation, and the TAG and total cholesterol concentrations in both the serum and liver. Additionally, oligonol attenuated oxidative stress through the inhibition of advanced glycation endproduct formation and its receptor expression. Furthermore, augmented expressions of NF-кBp65 and inducible NO synthase were down-regulated to the levels of $m / m$ mice in the group treated with oligonol at $20 \mathrm{mg} / \mathrm{kg}$. Regarding lipid metabolism, lower hepatic lipid resulted from the down-regulation of sterol regulatory element-binding protein- 1 and its target gene of lipogenic enzymes in the liver of $d b / d b$ mice. The present results suggest that oligonol has protective effects against ROS-related inflammation and excess lipid deposition in the type 2 diabetic liver.
\end{abstract}

Key words: Oligonol: Type 2 diabetes: Oxidative stress: Dyslipidaemia: Steatosis

Type 2 diabetes is associated with oxidative stress and abnormal lipid metabolism due to hyperglycaemia and hyperlipidaemia. Increased reactive oxygen species (ROS) generation and lipid peroxidation activate stress-sensitive intracellular signalling pathways such as the transcription of NF- $\mathrm{B}$, which plays a central role in inflammation-related disease $^{(1)}$. In addition, hyperglycaemia accelerates the formation of advanced glycation endproducts (AGE), which are proteins produced from non-enzymic glycation reactions ${ }^{(2)}$. $\mathrm{AGE}$ and their binding with receptors, such as the receptor for AGE (RAGE), galectin-3 and CD36, induce free radical formation. They accumulate during the normal ageing process and accelerated rates during the course of diabetes, and are associated with the pathogenesis of chronic diseases such as arthritis, atherosclerosis, liver cirrhosis and diabetic nephropathy ${ }^{(3)}$. Therefore, the attenuation of oxidative stress during the initiation and propagation of type 2 diabetes is important to prevent a vicious cycle of inflammatory responses and tissue damage. Moreover, insulin resistance in type 2 diabetes leads to a marked disruption of lipid dynamics, often reflected by elevated levels of circulating NEFA and TAG, together with excess fat deposition in various tissues ${ }^{(4)}$. Lipid homeostasis is regulated by a transcription factor, sterol regulatory elementbinding protein (SREBP), which is highly expressed in the presence of metabolic disorders such as obesity and diabetes. In particular, up-regulated SREBP-1 has been suggested to play a central role in the development of hepatic steatosis in an insulin-resistant animal model ${ }^{(5)}$. Accordingly, to prevent diabetic hepatic damage induced by inflammation and/or excess lipid accumulation, it is important to reduce oxidative stress and inhibit lipid synthesis in the liver.

Currently, functional food and/or dietary ingredients with health benefits are being given much attention due to the absence of adverse effects, abundant production and application to various commercial goods ${ }^{(6)}$. Oligonol is a phenolic product derived from lychee fruit extract containing catechin-type monomers and oligomers of proanthocyanidins, produced by a manufacturing process which converts

Abbreviations: ACC, acetyl-CoA carboxylase; AGE, advanced glycation endproduct; CEL, $N^{\varepsilon}$-(carboxyethyl)lysine; CML, $N^{\varepsilon}$-(carboxymethyl)lysine; COX-2, cyclo-oxygenase-2; FAS, fatty acid synthase; GSH, reduced glutathione; GSSG, oxidised glutathione; HMGR, 3-hydroxy-3-methylglutaryl-CoA reductase; iNOS, inducible NO synthase; RAGE, receptor for advanced glycation endproduct; ROS, reactive oxygen species; SREBP, sterol regulatory elementbinding protein; TBARS, thiobarbituric acid-reactive substance.

*Corresponding author: Dr Takako Yokozawa, fax +8176415 8841, email yokozawa@inm.u-toyama.ac.jp 
polyphenol polymers into oligomers ${ }^{(7,8)}$. Oligonol is produced by the oligomerisation of polyphenol polymers, typically proanthocyanidins; thus, oligonol delivers higher levels of oligomeric proanthocyanidins compared with fruit and plant sources that generally contain high-molecular-weight proanthocyanidins. There is accumulating evidence that oligonol can exert some biological effects in vitro and in vivo: anticancer $^{(9)}$, as well as antioxidant and anti-inflammatory effects $^{(10)}$, beneficial activity for NO bioavailability ${ }^{(11)}$ and a regulatory effect on lipid metabolism ${ }^{(12,13)}$. Indeed, dietary feeding with proanthocyanidins, which comprise oligonol, has been reported to induce a significant attenuation of tissue fat levels, without changing the total body mass of the animals compared with non-proanthocyanidin-fed animals ${ }^{(14)}$. However, there is no evidence to support whether or not oligonol has any effect on oxidative stress-induced inflammation and abnormal lipid accumulation in the liver of obesity-induced type 2 diabetes. Therefore, we investigated the effects of oligonol on hepatic damage induced by hyperglycaemia, abnormal lipid synthesis and NF-кB-related inflammation, using a typical type 2 diabetic animal, the C57BLKS/J $d b / d b$ mouse.

\section{Materials and methods}

\section{Oligonol}

Oligonol was generated by oligomerising polyphenol polymers derived from lychee fruit. The safety of oligonol as a food or dietary supplement and as a pharmaceutical additive has already been confirmed, as described previously ${ }^{(8)}$. Oligonol comprises a polyphenol mixture of $16.0 \%$ monomers (catechin, epicatechin, epicatechin gallate and epigallocatechin gallate) and $13.9 \%$ dimers (procyanidin A1, A2, B1 and B2), while lychee fruit polyphenols comprise a mixture of $6.4 \%$ monomers and $9.8 \%$ dimers. Oligonol is commercially available (Amino Up Chemical Co., Ltd, Sapporo, Japan).

\section{Materials}

Protease inhibitor mixture solution, 4,6-dihydroxy-2mercaptopyrimidine (2-thiobarbituric acid), EDTA, reduced glutathione (GSH) and oxidised glutathione (GSSG) were purchased from Wako Pure Chemical Industries, Ltd (Osaka, Japan). 2', $7^{\prime}$-Dichlorofluorescein diacetate was purchased from Molecular Probes (Eugene, OR, USA). The Bio-Rad protein assay kit and pure nitrocellulose membrane were purchased from Bio-Rad Laboratories (Tokyo, Japan). $\beta$-Actin, o-phthalaldehyde, phenylmethylsulfonyl fluoride and $N$-ethylmaleimide were purchased from Sigma Chemical Co. (St Louis, MO, USA). Rabbit polyclonal antibodies against PPAR $\alpha$, SREBP-1, SREBP-2, NF-кBp65 and RAGE, and mouse monoclonal antibody against cyclo-oxygenase-2 (COX-2) and inducible NO synthase (iNOS) were purchased from Santa Cruz Biotechnology, Inc. (Santa Cruz, CA, USA). Monoclonal anti- $N^{\varepsilon}$-(carboxyethyl)lysine (CEL) antibody and polyclonal anti- $N^{\varepsilon}$-(carboxymethyl)lysine (CML) antibody were kindly provided by Dr R. Nagai (Kumamoto University,
Kumamoto, Japan). Goat anti-rabbit and goat anti-mouse IgG horseradish peroxidase-conjugated secondary antibodies were purchased from Santa Cruz Biotechnology, Inc. ECL ${ }^{\mathrm{TM}}$ Western Blotting Detection Reagents were purchased from Amersham Bioscience (Piscataway, NJ, USA).

\section{Experimental protocol}

The 'Guidelines for Animal Experimentation' approved by the University of Toyama were followed in the present study (registration no. S-2006 INM-22). Male C57BLKS/J $d b / d b$ and age-matched $\mathrm{m} / \mathrm{m}$ mice, aged 5 weeks, were purchased from Japan SLC Inc. (Hamamatsu, Japan). C57BLKS/J $\mathrm{m} / \mathrm{m}$ mice were used as a normal control in the experiment. Mice were maintained under a $12 \mathrm{~h}$ light-dark cycle, fed a standard laboratory pellet chow (comprising $24.0 \%$ protein, $3.5 \%$ lipids and $60.5 \%$ carbohydrate; CLEA Japan Inc., Tokyo, Japan) and water ad libitum, and housed in a room with a controlled temperature $\left(23 \pm 3^{\circ} \mathrm{C}\right)$ and humidity (about $60 \%$ ). Oligonol ( 10 or $20 \mathrm{mg} / \mathrm{kg}$ body weight per d) was orally administered to $d b / d b$ mice (Oligo-10 or Oligo-20, $n 10$, respectively), while vehicle-treated $d b / d b$ ( $n$ 10) and non-diabetic control $m / m$ ( $n$ 6) mice received water every day for 8 weeks. The body weight, food intake and water intake were measured every day during the treatment period. After 8 weeks of oligonol treatment, blood samples were collected from anaesthetised mice by cardiac puncture. The serum was immediately separated from blood samples by centrifugation. Subsequently, to remove the remaining blood in the liver, each mouse was perfused with ice-cold physiological saline by syringe after cardiac puncture, and the liver was harvested, plunged into liquid $\mathrm{N}_{2}$ and stored at $-80^{\circ} \mathrm{C}$ until analysis.

\section{Measurement of serum parameters}

Serum glucose, TAG, total cholesterol and NEFA levels were measured using a commercial kit (Glucose CII-Test, Triglyceride E-Test, Cholesterol E-Test and NEFA C-Test from Wako Pure Chemical Industries, Ltd, Osaka, Japan). The serum ROS level was determined using the method of Ali et al. ${ }^{(15)}$ and the thiobarbituric acid-reactive substance (TBARS) concentration was examined employing the method of Naito \& Yamanaka ${ }^{(16)}$. Hepatic functional parameters (alanine aminotransferase and aspartate aminotransferase) were measured using a Wako kit (Transaminase CII-Test).

\section{Measurement of hepatic TAG and total cholesterol contents}

Hepatic tissues were homogenised in ice-cold $0.9 \% \mathrm{NaCl}$ buffer. Then the homogenate was extracted with a mixture of chloroform and methanol $(2: 1, \mathrm{v} / \mathrm{v})$ according to the method of Folch et al. ${ }^{(17)}$, and the mixture was centrifuged at $1670 \mathrm{~g}$ for $15 \mathrm{~min}$. The organic layer was collected and dried, and the residue was dissolved in isopropanol. Determinations for TAG and total cholesterol contents were performed using the Wako kit. 
Assessment of hepatic reactive oxygen species generation and thiobarbituric acid-reactive substance levels

ROS generation was measured using the method of Ali et $a l^{(15)}$. Hepatic tissues were homogenised on ice with 1 mm-EDTA-50 mm-sodium phosphate buffer ( $\mathrm{pH} 7 \cdot 4$ ), and then $25 \mathrm{~mm}-2^{\prime}, 7^{\prime}$-dichlorofluorescein diacetate was added to homogenates. After incubation for $30 \mathrm{~min}$, the changes in fluorescence values were determined at an excitation wavelength of $486 \mathrm{~nm}$ and emission wavelength of $530 \mathrm{~nm}$. The hepatic TBARS content, an oxidative stress biomarker, was determined employing the method of Mihara \& Uchiyama ${ }^{(18)}$.

\section{Determination of hepatic reduced glutathione and oxidised glutathione levels}

GSH and GSSG assays were carried out applying the method of Hissin \& Hilf ${ }^{(19)}$. Hepatic tissues were homogenised on ice with $1 \mathrm{~mm}$-EDTA-50 mm-sodium phosphate buffer ( $\mathrm{pH} 7 \cdot 4$ ). Then, $25 \%$ metaphosphoric acid was added for protein precipitation. The homogenate was centrifuged at $4^{\circ} \mathrm{C}$ at $100000 \mathrm{~g}$ for $30 \mathrm{~min}$ to obtain the supernatant fraction for the assays of GSH and GSSG. To assay GSH, $1 \mathrm{~mm}$-EDTA-50 mm-sodium phosphate buffer ( $\mathrm{pH} 7 \cdot 4$ ) was added to the supernatant fraction, followed by the addition of $o$-phthalaldehyde. After $20 \mathrm{~min}$ at room temperature, fluorescence was estimated at an excitation wavelength of $360 \mathrm{~nm}$ and emission wavelength of $460 \mathrm{~nm}$. GSSG was assayed after pre-incubation with $N$-ethylmaleimide for $20 \mathrm{~min}$, and $0 \cdot 1 \mathrm{M}-\mathrm{NaOH}$ was substituted for the phosphate buffer. After incubation for $20 \mathrm{~min}$ at room temperature, the fluorescence value was estimated at an excitation wavelength of $360 \mathrm{~nm}$ and emission wavelength of $460 \mathrm{~nm}$. Protein assays were carried out according to the method of Itzhaki \& Gill ${ }^{(20)}$ using bovine serum albumin as a standard.

\section{Preparation of nuclear and post-nuclear fractions}

To prepare nuclear fractions, hepatic tissues were homogenised with ice-cold lysis buffer containing $5 \mathrm{~mm}$-2-amino2-hydroxymethyl-propane-1,3-diol (Tris)-HCl (pH 7.5),

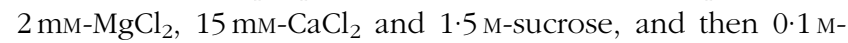
dithiothreitol (DTT) and protease inhibitor cocktail were added. After centrifugation $\left(10500 \mathrm{~g}\right.$ for $20 \mathrm{~min}$ at $4^{\circ} \mathrm{C}$ ), the pellet was suspended with extraction buffer containing $20 \mathrm{~mm}$-2-[4-(2-hydroxyethyl)-1-piperazyl] ethanesulfonic acid

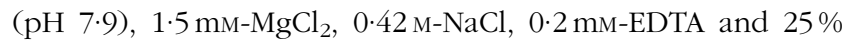
$(\mathrm{v} / \mathrm{v})$ glycerol, and then $0 \cdot 1 \mathrm{M}-\mathrm{DTT}$ and protease inhibitor cocktail were added. The mixture was placed on ice for $30 \mathrm{~min}$. The nuclear fraction was prepared by centrifugation at $20500 \mathrm{~g}$ for $5 \mathrm{~min}$ at $4^{\circ} \mathrm{C}$. The post-nuclear fraction was extracted from the liver of each mouse, as described below. In brief, hepatic tissue was homogenised with ice-cold lysis buffer (pH 7.4) containing $137 \mathrm{~mm}-\mathrm{NaCl}, 20 \mathrm{~mm}-$ Tris- $\mathrm{HCl}, 1 \%$ Tween 20, $10 \%$ glycerol, 1 mm-phenylmethylsulfonyl fluoride and protease inhibitor mixture solution. The homogenate was then centrifuged at $2000 \mathrm{~g}$ for $10 \mathrm{~min}$ at $4^{\circ} \mathrm{C}$. The protein concentration of each fraction was determined using a commercial kit (Bio-Rad Laboratories, Hercules, CA, USA).

\section{Western blot analyses}

For the determination of NF-кB, PPAR $\alpha$, SREBP-1 and SREBP-2, $30 \mu \mathrm{g}$ protein of each nuclear fraction was electrophoresed through $8 \%$ SDS-PAGE. Separated proteins were transferred to a nitrocellulose membrane, blocked with $5 \%(\mathrm{w} / \mathrm{v})$ skimmed milk solution for $1 \mathrm{~h}$, and then incubated with primary antibodies to NF- $\mathrm{BP} 65$, PPAR $\alpha$, SREBP-1, SREBP-2 and $\beta$-actin, respectively, overnight at $4^{\circ} \mathrm{C}$. After the blots were washed, they were incubated with anti-rabbit or antimouse IgG horseradish peroxidase-conjugated secondary antibody for $1.5 \mathrm{~h}$ at room temperature. Also, $30 \mu \mathrm{g}$ of protein of each post-nuclear fraction for COX-2, iNOS, RAGE, CEL and CML were electrophoresed through 8\% SDS-PAGE. Each antigen-antibody complex was visualised using ECL Western Blotting Detection Reagents and detected by chemiluminescence with LAS-4000 (Fujifilm, Tokyo, Japan). Band densities were determined using ATTO Densitograph Software (ATTO Corporation, Tokyo, Japan) and quantified as the ratio to $\beta$-actin. These protein levels of groups are expressed relative to those of $\mathrm{m} / \mathrm{m}$ mice (represented as 1 ).

\section{Quantitative real-time PCR}

Total RNA was isolated from hepatic tissue using Trizol reagent (Invitrogen Life Technologies, Carlsbad, CA, USA) and quantified with NanoDrop (Thermo Scientific, Wilmington, DE, USA). The CDNA were synthesised from $5 \mu \mathrm{g}$ of RNA using RT (QIAGEN, Tokyo, Japan). For the real-time PCR, triplicate samples of serially diluted cDNA samples were used in a reaction mixture that contained $1 \mu \mathrm{M}$ of each primer in a reaction volume of $50 \mu \mathrm{l}$ using the SYBR Green Real-time PCR kit (QIAGEN, Tokyo, Japan) and a fluorometric thermal cycler (Mx3000P ${ }^{\mathrm{TM}}$; Stratagene, La Jolla, CA, USA). Reaction mixtures were incubated for an initial denaturation at $95^{\circ} \mathrm{C}$ for $15 \mathrm{~min}$, followed by forty-five cycles at $94^{\circ} \mathrm{C}$ for $15 \mathrm{~s}, 60^{\circ} \mathrm{C}$ for $30 \mathrm{~s}$ and $72^{\circ} \mathrm{C}$ for $30 \mathrm{~s}$. Primers used were as follows: acetylCoA carboxylase (ACC; sense: CCCAGCAGAATAAAGCTACTTTGG, antisense: TCCTTTTGTGCAACTAGGAACGT), fatty acid synthase (FAS; sense: CCTGGATAGCATTCCGAACCT, antisense: AGCACATCTCGAAGGCTACACA) and 3-hydroxy-3methylglutaryl-CoA reductase (HMGR; sense: AGCCGAAGCAGCACATGAT, antisense: CTTGTGGAATGCCTTGTGATTG). Glyceraldehyde 3-phosphate dehydrogenase (GAPDH) was employed as an endogenous control. The $\Delta \mathrm{C}_{\mathrm{T}}$ method was used for relative quantification. The $\Delta \mathrm{C}_{\mathrm{T}}$ value for each sample was determined by calculating the difference between the $\mathrm{C}_{\mathrm{T}}$ value of the target gene and that of the GAPDH reference gene. The normalised target gene expression level in the sample was calculated using the formula $2^{-\Delta \Delta C T}$ as the fold change over the control.

\section{Histology}

The excised parts of livers were immediately fixed with $10 \%$ neutral-buffered formalin and, after embedding in paraffin, they were cut into $5 \mu \mathrm{m}$-thick sections. After oil red $\mathrm{O}$ staining, these sections were examined with a light microscope. 


\section{Statistical analysis}

Data are expressed as mean values with their standard errors. Statistical comparisons were performed by one-way ANOVA followed by Duncan's multiple-range test. Statistical analysis was conducted using SAS (release 9.2; SAS Institute, Inc., Cary, NC, USA) and $P<0.05$ was considered significant.

\section{Results}

\section{General characteristics}

Type 2 diabetic characteristics such as excessive body-weight gain, food intake and water intake were exhibited in $d b / d b$ mice at age 17 weeks compared with normal $\mathrm{m} / \mathrm{m}$ mice (Table 1). The liver weight was higher in $d b / d b$ than $m / m$ mice; however, oligonol administrations led to no significant differences in $d b / d b$ groups. In serum analyses, glucose and lipid concentrations were increased in $d b / d b$ compared with $\mathrm{m} / \mathrm{m}$ mice; however, except for serum glucose, oligonol administration significantly reduced serum concentrations of TAG, total cholesterol and NEFA at $20 \mathrm{mg} / \mathrm{kg}$ doses (Table 1). In addition, oxidative stress-related parameters, ROS and TBARS, were enhanced in vehicle $d b / d b$ compared with $\mathrm{m} / \mathrm{m}$ mice. However, oligonol treatment at $20 \mathrm{mg} / \mathrm{kg}$ significantly reduced the ROS level and inhibited lipid peroxidation in the serum of $d b / d b$ mice (Table 1 ). Regarding hepatic functional parameters, serum alanine aminotransferase and aspartate aminotransferase levels in vehicle $d b / d b$ mice were elevated compared with $\mathrm{m} / \mathrm{m}$ mice, while, in oligonoladministered $d b / d b$ mice, only the alanine aminotransferase level was significantly decreased (Table 1 ).

\section{Hepatic biomarkers associated with oxidative stress}

As shown in Fig. 1, the hepatic levels of ROS and TBARS in vehicle-treated $d b / d b$ mice were apparently higher than those of $\mathrm{m} / \mathrm{m}$ mice, whereas these enhanced levels were significantly reduced by oligonol treatment in a dosedependent manner. Concerning the hepatic GSH, GSSG and GSH:GSSG ratio, there were significant alterations between vehicle $d b / d b$ and $m / m$ groups. Oligonol administration significantly augmented the GSH:GSSG ratio due to a marked decrease in the GSSG level in the liver of $d b / d b$ mice.

\section{Hepatic NF-кBp65, cyclo-oxygenase-2 and inducible NO synthase expressions}

At the end of the experiment, hepatic NF-кBp65- and NF-кBmediated target protein expression levels in the vehicletreated $d b / d b$ group were significantly up-regulated compared with those in the $\mathrm{m} / \mathrm{m}$ group (Fig. 2). The administration of oligonol suppressed the transcription of NF- $\mathrm{BB}$ in the liver. Also, up-regulated hepatic iNOS expression levels were reduced on oligonol treatment at $20 \mathrm{mg} / \mathrm{kg}$. Concerning hepatic COX-2 protein expression, oligonol treatment showed a reducing tendency, but this was not significant.

\section{Hepatic receptor for advanced glycation endproducts, $\mathrm{N}^{\varepsilon}$-(carboxyethyl)lysine and $\mathrm{N}^{\varepsilon}$-(carboxymethyl)lysine expressions}

In Fig. 3, protein expressions of AGE-related proteins were enhanced in the $d b / d b$ mouse liver at 17 weeks. The $d b / d b$ mice showed up-regulated protein expressions of RAGE and CML, but the oral administration of oligonol attenuated these protein levels. Hepatic CEL protein expression remained unchanged in all experimental groups.

\section{Hepatic TAG and total cholesterol contents}

The hepatic contents of TAG and total cholesterol in vehicletreated $d b / d b$ mice were significantly elevated compared

Table 1. General characteristics and serum analyses after 8 weeks' treatment with oligonol

(Mean values with their standard errors)

\begin{tabular}{|c|c|c|c|c|c|c|c|c|}
\hline \multirow[b]{3}{*}{ Item } & & & \multicolumn{6}{|c|}{$d b / d b$} \\
\hline & \multicolumn{2}{|c|}{$m / m$} & \multicolumn{2}{|c|}{ Veh } & \multicolumn{2}{|c|}{ Oligo-10 } & \multicolumn{2}{|c|}{ Oligo-20 } \\
\hline & Mean & SE & Mean & SE & Mean & SE & Mean & SE \\
\hline Body-weight gain (g/8 weeks) & $1 \cdot 8^{\mathrm{b}}$ & 0.5 & $9 \cdot 6^{\mathrm{a}}$ & $1 \cdot 7$ & $7 \cdot 9^{a}$ & 0.6 & $9 \cdot 8^{a}$ & $0 \cdot 7$ \\
\hline Food intake $(\mathrm{g} / \mathrm{d})$ & $3 \cdot 10^{b}$ & 0.04 & $5 \cdot 80^{\mathrm{a}}$ & 0.05 & $5 \cdot 82^{\mathrm{a}}$ & 0.06 & $5 \cdot 99^{a}$ & 0.07 \\
\hline Water intake $(\mathrm{ml} / \mathrm{d})$ & $4 \cdot 5^{\mathrm{b}}$ & 0.6 & $13 \cdot 6^{\mathrm{a}}$ & 0.7 & $14 \cdot 5^{\mathrm{a}}$ & $1 \cdot 1$ & $13 \cdot 3^{a}$ & $1 \cdot 0$ \\
\hline Liver weight (g/100 g body weight) & $4.47^{b}$ & 0.57 & $7 \cdot 18^{\mathrm{a}}$ & 0.40 & $6 \cdot 23^{a}$ & 0.41 & $6 \cdot 70^{\mathrm{a}}$ & 0.24 \\
\hline Glucose (mg/l) & $1529^{b}$ & 122 & $5940^{\mathrm{a}}$ & 293 & $5712^{a}$ & 611 & $6684^{\mathrm{a}}$ & 409 \\
\hline TAG $(\mathrm{mg} / \mathrm{l})$ & $752^{b}$ & 60 & $2198^{a}$ & 181 & $1970^{a}$ & 300 & $1608^{b}$ & 202 \\
\hline Total cholesterol (mg/l) & $760^{b}$ & 37 & $1568^{\mathrm{a}}$ & 126 & $1387^{\mathrm{a}}$ & 82 & $1242^{b}$ & 65 \\
\hline $\operatorname{NEFA}(\mathrm{mEq} / \mathrm{l})$ & $0.74^{b}$ & 0.10 & $1.41^{\mathrm{a}}$ & 0.08 & $1 \cdot 18^{a}$ & 0.13 & $1 \cdot 10^{b}$ & 0.09 \\
\hline ROS (fluorescence/min per ml) & $170 \cdot 7^{b}$ & $27 \cdot 0$ & $321 \cdot 0^{\mathrm{a}}$ & $42 \cdot 3$ & $213 \cdot 8^{b}$ & $24 \cdot 2$ & $144 \cdot 8^{b}$ & $23 \cdot 5$ \\
\hline TBARS (nmol MDA/ml) & $5 \cdot 70^{\mathrm{c}}$ & 0.15 & $14.93^{\mathrm{a}}$ & 1.33 & $13 \cdot 35^{a}$ & $1 \cdot 14$ & $7.09^{b}$ & 0.29 \\
\hline ALT (IU/I) & $66 \cdot 6^{\mathrm{c}}$ & $4 \cdot 3$ & $146 \cdot 6^{\mathrm{a}}$ & $10 \cdot 9$ & $127 \cdot 6^{a}$ & $7 \cdot 2$ & $77 \cdot 19^{\mathrm{b}}$ & $4 \cdot 37$ \\
\hline AST (IU/I) & $11 \cdot 24^{c}$ & 0.33 & $35 \cdot 72^{a}$ & 3.51 & $29 \cdot 25^{b}$ & 1.56 & $27 \cdot 66^{b}$ & 1.56 \\
\hline
\end{tabular}


(A)

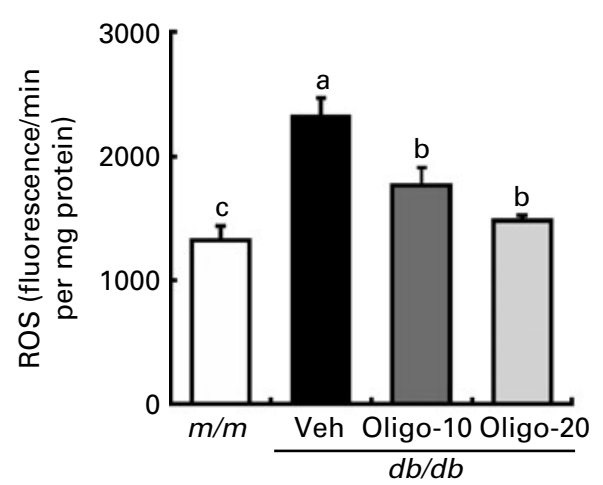

(C)

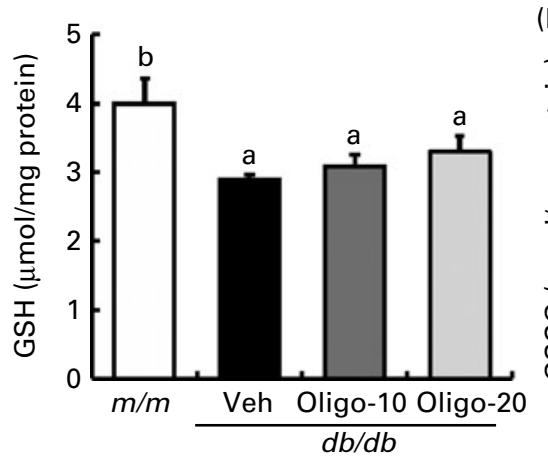

(B)

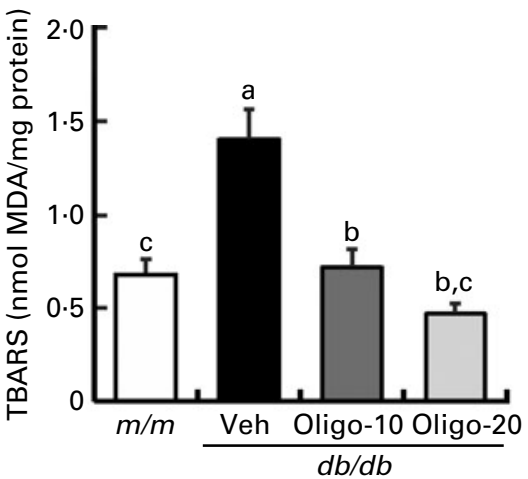

(D)

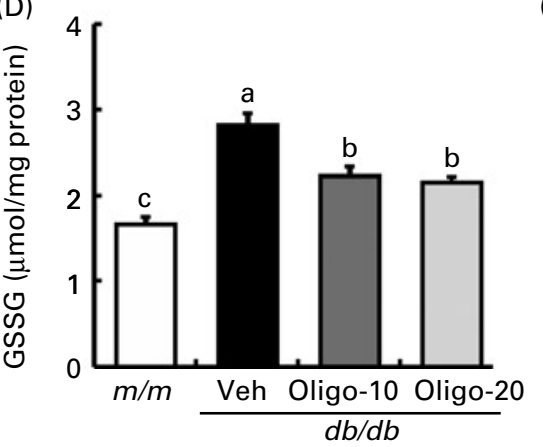

(E)

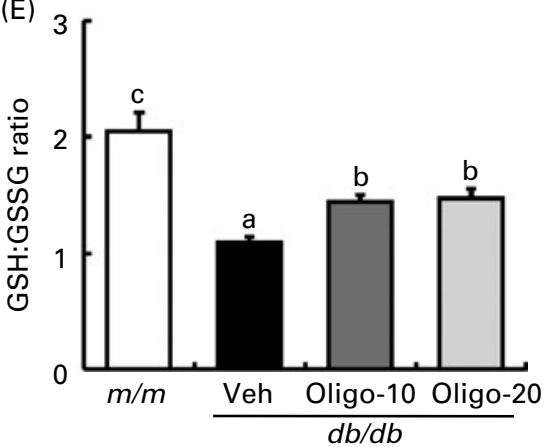

Fig. 1. Biomarkers associated with oxidative stress in the liver: (A) reactive oxygen species (ROS); (B) thiobarbituric acid-reactive substances (TBARS); (C) reduced glutathione (GSH); (D) oxidised glutathione (GSSG); (E) GSH:GSSG ratio. $m / m$, Misty; $d b / d b$, diabetic; Veh, $d b / d b$ vehicle-treated mice; Oligo-10, $d b / d b$ mice treated with oligonol at $10 \mathrm{mg} / \mathrm{kg}$ body weight; Oligo-20, $d \mathrm{db} / \mathrm{db}$ mice treated with oligonol at $20 \mathrm{mg} / \mathrm{kg}$ body weight; MDA, malondialdehyde. Values are means ( $n 6$ or $n 10)$, with standard errors represented by vertical bars. ${ }^{\mathrm{a}, \mathrm{b}, \mathrm{c}}$ Mean values with unlike letters were significantly different $(P<0 \cdot 05$; Duncan's test).

with $\mathrm{m} / \mathrm{m}$ mice (Fig. 4). In the oligonol-treated group, hepatic TAG and total cholesterol contents were markedly decreased on oligonol administration.

\section{Hepatic lipogenic enzyme mRNA expressions}

To examine the effects of oligonol administration on the hepatic mRNA levels of genes involved in fatty acid and cholesterol synthesis, quantitative real-time PCR was performed (Fig. 5). mRNA expressions of lipogenic enzymes for TAG synthesis (ACC and FAS) and cholesterol synthesis (HMGR) were over-expressed in the hepatic tissue of vehicle $d b / d b$ mice compared with the $m / m$ group. However, oligonol-treated $d b / d b$ mice exhibited significantly lower expressions of ACC, FAS and HMGR than $d b / d b$ vehicle mice.
(A)
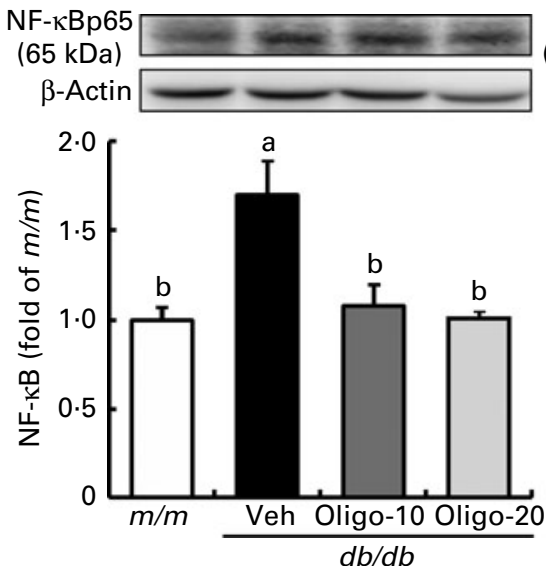

(B)
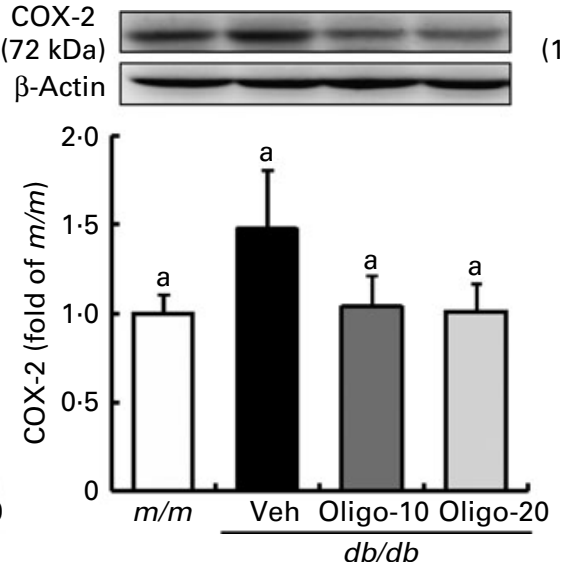

(C)
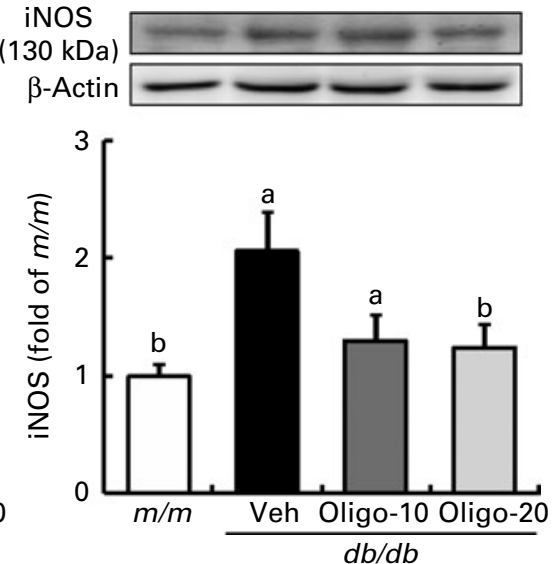

Fig. 2. NF-кBp65 (A), cyclo-oxygenase-2 (COX-2) (B) and inducible NO synthase (iNOS) (C) expressions in the liver. $m / m$, Misty; $d b / d b$, diabetic; Veh, $d b / d b$ vehicle-treated mice; Oligo-10, $d b / d b$ mice treated with oligonol at $10 \mathrm{mg} / \mathrm{kg}$ body weight; Oligo-20, $d \mathrm{~b} / \mathrm{db}$ mice treated with oligonol at $20 \mathrm{mg} / \mathrm{kg}$ body weight. Values are means ( $n 6$ or $n 10)$, with standard errors represented by vertical bars. ${ }^{a, b}$ Mean values with unlike letters were significantly different $(P<0 \cdot 05$; Duncan's test). 
(A)

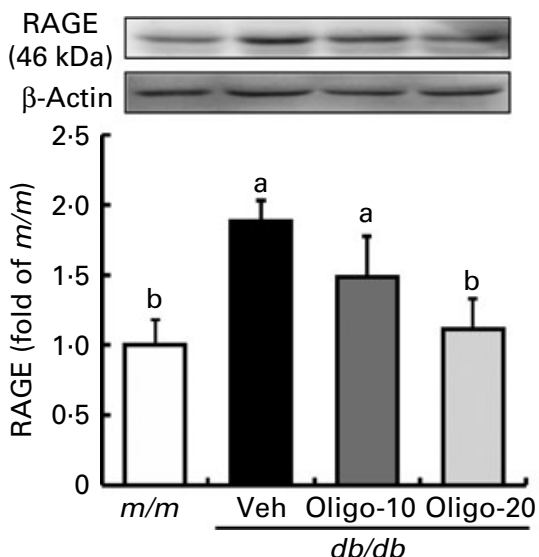

(B)
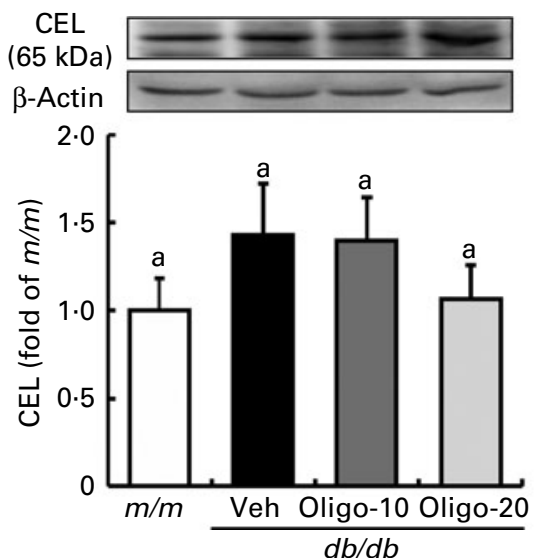

(C)

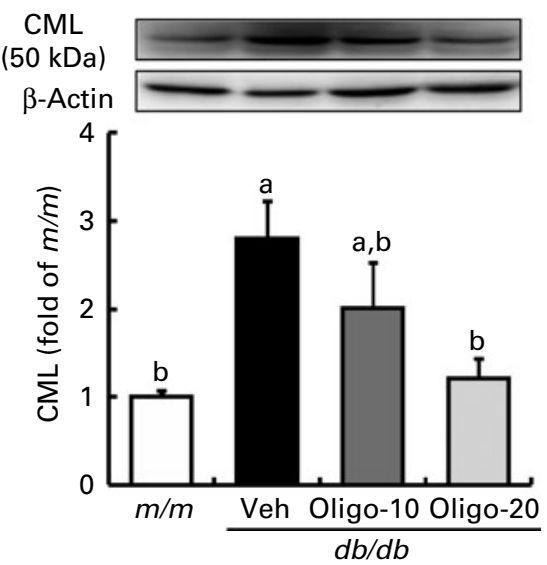

Fig. 3. Receptor for advanced glycation endproduct (RAGE) (A), $N^{\varepsilon}$-(carboxyethyl)lysine (CEL) (B) and $N^{\varepsilon}$-(carboxymethyl)lysine (CML) (C) expressions in the liver. $\mathrm{m} / \mathrm{m}$, Misty; $d b / d b$, diabetic; Veh, $d b / d b$ vehicle-treated mice; Oligo-10, $d b / d b$ mice treated with oligonol at $10 \mathrm{mg} / \mathrm{kg}$ body weight; Oligo-20, $d b / d b$ mice treated with oligonol at $20 \mathrm{mg} / \mathrm{kg}$ body weight. Values are means ( $n 6$ or $n 10)$, with standard errors represented by vertical bars. ${ }^{\text {a,b }}$ Mean values with unlike letters were significantly different $(P<0.05$; Duncan's test).

\section{Hepatic PPAR $\alpha$, sterol regulatory element-binding protein-1 and sterol regulatory element-binding protein-2 expressions}

As shown in Fig. 6, hepatic expressions of transcriptional factors related to lipid regulation, PPAR $\alpha$, SREBP-1 and SREBP-2, were examined by Western blotting. There was no alteration in PPAR $\alpha$ and SREBP-2 expressions in the livers of all experimental groups of mice. SREBP-1 protein expression was higher in vehicle $d b / d b$ than $m / m$ mice, but, in the group treated with oligonol at $20 \mathrm{mg} / \mathrm{kg}$, hepatic SREBP-1 expression was significantly decreased (Fig. 6).

\section{Histological examinations}

Fig. 7 shows the results of histological examinations using oil red $\mathrm{O}$ staining, which detects fat deposits. The level of lipid deposition was higher in the liver of $d b / d b$ control mice compared with that of $m / m$ mice. However, oligonol-treated $d b / d b$ mice clearly showed decreased fat accumulation.

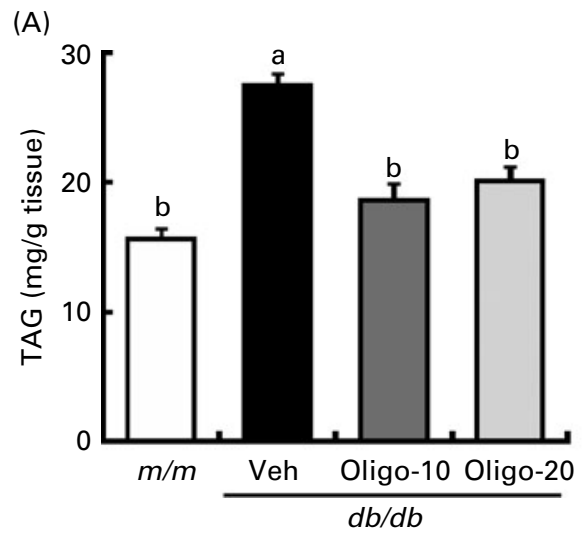

\section{Discussion}

Hyperglycaemia and elevated NEFA levels result in the generation of ROS, and, consequently increase oxidative stress $^{(21)}$. ROS are believed to play a direct, key role in the pathogenesis of diabetic complications, because of their ability to directly oxidise and damage DNA, protein and lipids, consequently resulting in cell dysfunction and apoptosis $^{(22,23)}$. In the present results, the experimental type 2 diabetes model mice exhibited higher oxidative stress levels caused by increased ROS and lipid peroxidation, along with a lower hepatic GSH:GSSG ratio, compared with normal $\mathrm{m} / \mathrm{m}$ mice. Conversely, oligonol treatment significantly reduced ROS and TBARS levels in both the serum and liver of $d b / d b$ mice. In addition, the reduced GSH:GSSG ratio of vehicle $d b / d b$ mice was increased by oligonol administration due to a reduction of the GSSG concentration in the liver. Actually, oligonol comprises catechin-type monomers and oligomers, which have well-recognised antioxidant and radical-scavenging effects

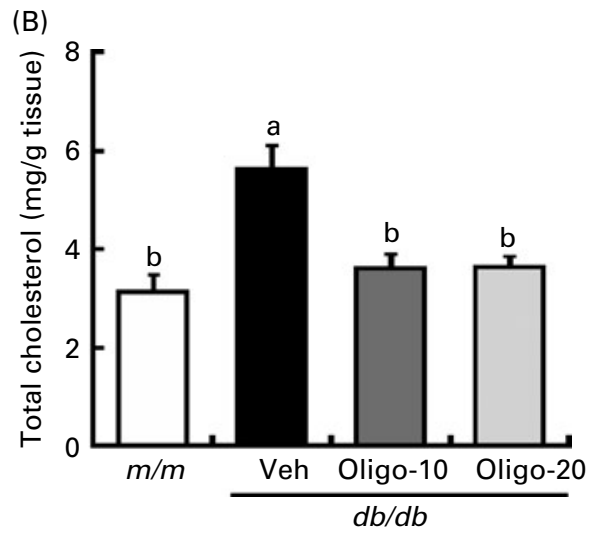

Fig. 4. Hepatic TAG (A) and total cholesterol (B) contents. $m / m$, Misty; $d b / d b$, diabetic; Veh, $d b / d b$ vehicle-treated mice; Oligo-10, $d b / d b$ mice treated with oligonol at $10 \mathrm{mg} / \mathrm{kg}$ body weight; Oligo-20, $\mathrm{db} / \mathrm{db}$ mice treated with oligonol at $20 \mathrm{mg} / \mathrm{kg}$ body weight. Values are means ( $n 6$ or $n 10$ ), with standard errors represented by vertical bars. ${ }^{\mathrm{a}, \mathrm{b}}$ Mean values with unlike letters were significantly different $(P<0 \cdot 05$; Duncan's test). 

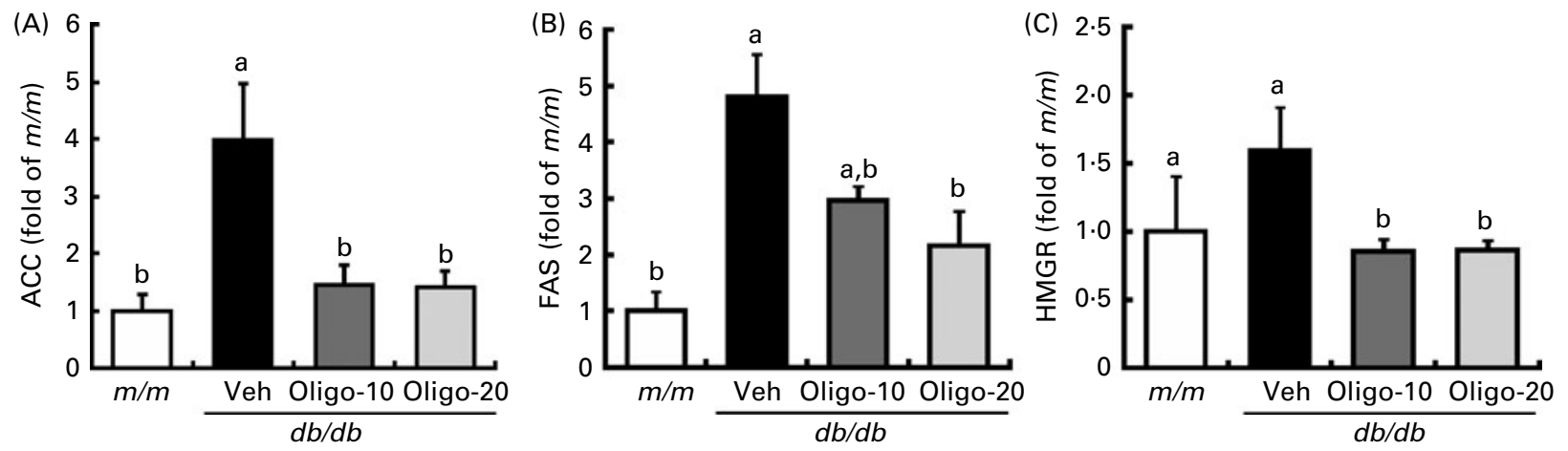

Fig. 5. Hepatic mRNA expressions of acetyl-CoA carboxylase (ACC) (A), fatty acid synthase (FAS) (B) and 3-hydroxy-3-methylglutaryl-CoA reductase (HMGR) (C). $\mathrm{m} / \mathrm{m}$, Misty; $d b / d b$, diabetic; Veh, $d b / d b$ vehicle-treated mice; Oligo-10, $d b / d b$ mice treated with oligonol at $10 \mathrm{mg} / \mathrm{kg}$ body weight; Oligo-20, $d b / d b$ mice treated with oligonol at $20 \mathrm{mg} / \mathrm{kg}$ body weight. Values are means ( $n 6$ or $n 10)$, with standard errors represented by vertical bars. ${ }^{\text {a,b }}$ Mean values with unlike letters were significantly different $(P<0.05$; Duncan's test).

in vitro and in vivo ${ }^{(24,25)}$. Consequently, these results demonstrate that oligonol effectively attenuated oxidative stress, at least in part, through the direct inhibition of ROS and lipid peroxidation rather than the improvement of hyperglycaemia.

In type 2 diabetes, the redox-sensitive intracellular signalling pathway is altered. In particular, one major intracellular target of hyperglycaemia and oxidative stress is the transcription factor NF- $\mathrm{BB}$. NF- $\mathrm{KB}$ can be activated by a wide array of exogenous and endogenous stimuli including hyperglycaemia, elevated NEFA, ROS, TNF- $\alpha$, IL- $1 \beta$, other proinflammatory cytokines, AGE-binding RAGE and p38 mitogen-activated protein kinase. The activation of $\mathrm{NF}-\kappa \mathrm{B}$ induces the inflammation-related proteins COX-2 and iNOS, and subsequent production of $\mathrm{PG}$ and $\mathrm{NO}$, respectively. $\mathrm{NO}$ reacts very rapidly with superoxide to form peroxynitrite and other NO-derived oxidants capable of damaging DNA and proteins ${ }^{(26)}$. There is a vicious cycle involving NF- $\mathrm{B}$, oxidative stress and inflammation under the diabetic condition. Therefore, the inhibition of NF- $\mathrm{KB}$ transcription plays a central role in regulating the pathophysiology of diabetic complications. In the present study, elevated protein expressions of NF-кBp65 and iNOS in the liver of $d b / d b$ mice were markedly down-regulated by oligonol administration. Oligonol administration could adjust inflammation through the inhibition of the NF- $\mathrm{B}$ pathway.

Hyperglycaemia in diabetes accelerates the synthesis and tissue deposition of AGE, an abnormality contributing to the pathogenesis of morbid complications. The progression of AGE generation was also stimulated by enhanced oxidative stress because ROS induce the auto-oxidation of Amadori products, and a decrease in GSH levels impairs the activity of glyoxalase, the major AGE-detoxifying enzyme ${ }^{(27)}$. Two distinctive AGE, CEL and CML, are formed on proteins by glycoxidation and/or lipid peroxidation pathways. AGEmodified molecules interact with specific cell-surface receptors (RAGE), activating several intracellular signal transduction pathways such as the induction of NF- $\mathrm{B}$ transcription and mitogen-activated protein kinase followed by the further stimulation of oxidative stress and inflammatory responses ${ }^{(28)}$.
(A)
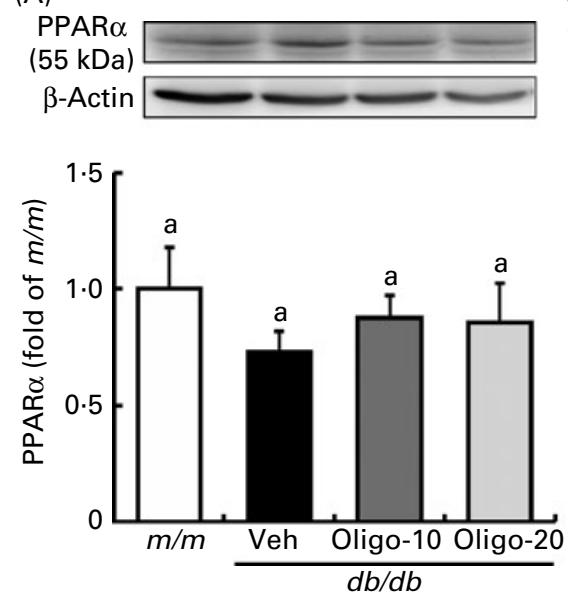

(B)

SREBP-1

$(68 \mathrm{kDa})$

$\beta$-Actin

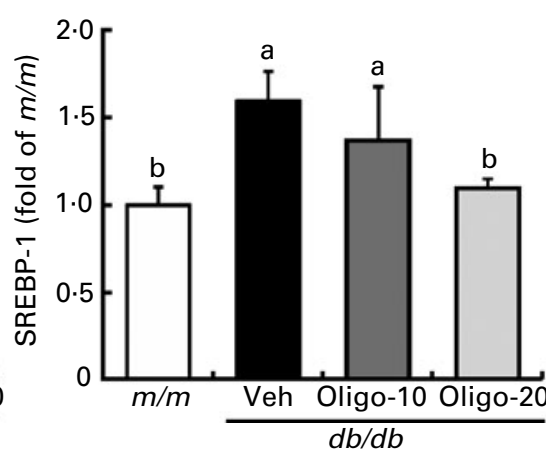

(C)
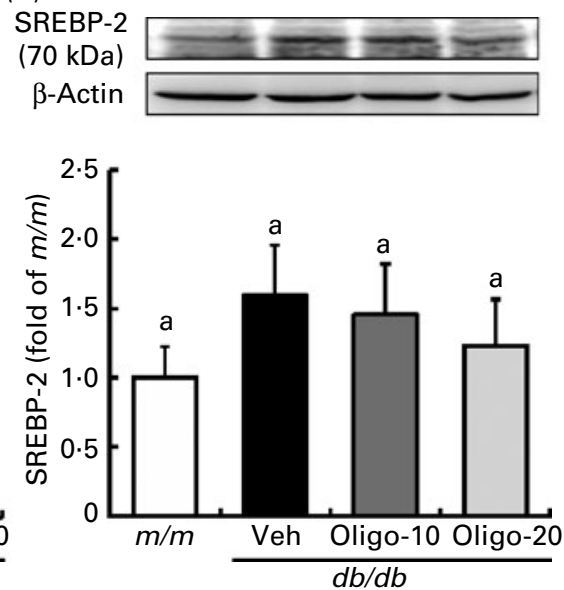

Fig. 6. PPAR $\alpha$ (A), sterol regulatory element-binding protein (SREBP)-1 (B) and SREBP-2 (C) expressions in the liver. $m / m, \mathrm{Misty}$; $d b / d b$, diabetic; Veh, $d b / d b$ vehicle-treated mice; Oligo-10, $d b / d b$ mice treated with oligonol at $10 \mathrm{mg} / \mathrm{kg}$ body weight; Oligo-20, db/db mice treated with oligonol at $20 \mathrm{mg} / \mathrm{kg}$ body weight. Values are means ( $n 6$ or $n 10)$, with standard errors represented by vertical bars. ${ }^{a, b}$ Mean values with unlike letters were significantly different $(P<0.05$; Duncan's test). 

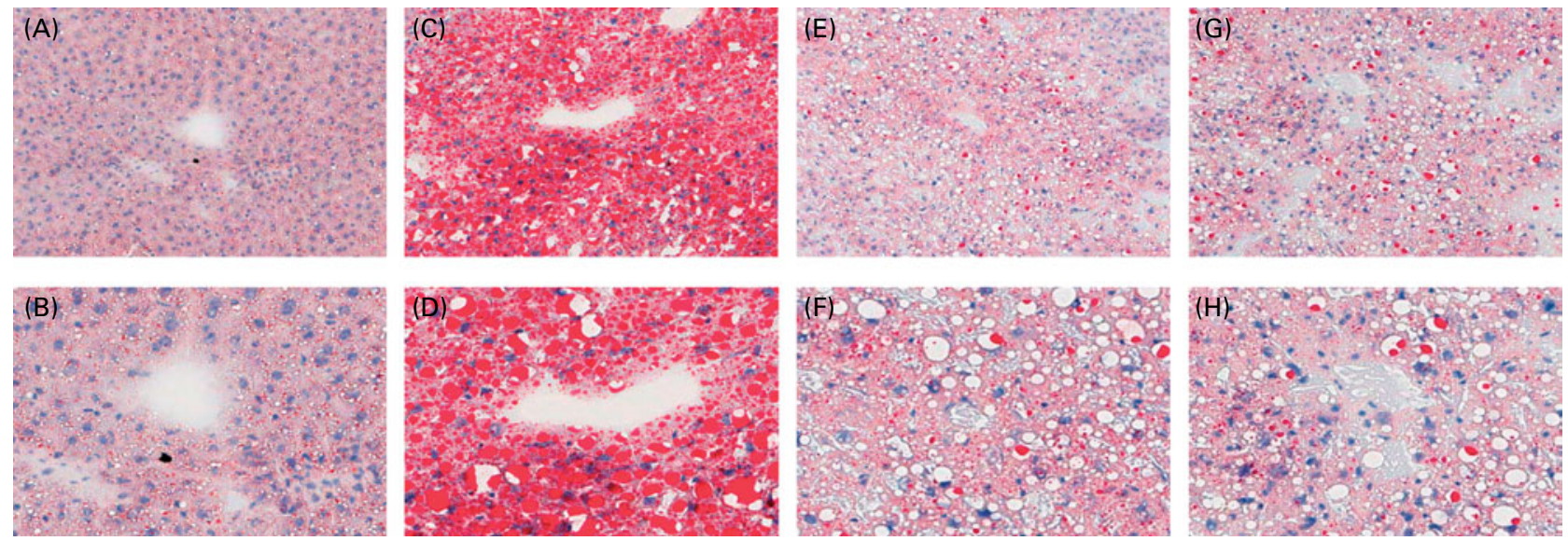

Fig. 7. Oil red $\mathrm{O}$ staining of the liver. Upper panel $(\mathrm{A}, \mathrm{C}, \mathrm{E}, \mathrm{G}), \times 20$; lower panel $(\mathrm{B}, \mathrm{D}, \mathrm{F}, \mathrm{H}), \times 40$. (A and B) Misty $(\mathrm{m} / \mathrm{m}) \mathrm{mice}$; $(\mathrm{C}$ and $\mathrm{D})$ diabetic $(\mathrm{db} / \mathrm{db})$ vehicle-treated mice; ( $E$ and $F) d b / d b$ mice treated with oligonol at $10 \mathrm{mg} / \mathrm{kg}$ body weight; $(\mathrm{G}$ and $\mathrm{H}) \mathrm{db} / \mathrm{db}$ mice treated with oligonol at $20 \mathrm{mg} / \mathrm{kg}$ body weight.

Moreover, up-regulated RAGE expression is related to hepatic fibrogenesis through a parallel increase in transforming growth factor- $\beta_{1}$ and procollagen, which play central roles in fibrosis progression ${ }^{(29)}$. The present study showed that oligonol was effective at attenuating oxidative stress and inhibiting NF-кB transcription. Therefore, oligonol was assumed to down-regulate AGE-related protein expression in the liver. In Western blot analysis, hepatic RAGE, CEL and CML expressions in $d b / d b$ mice were elevated, compared with those in $\mathrm{m} / \mathrm{m}$ mice. However, oligonol administration significantly attenuated RAGE and CML expressions in the liver of $d b / d b$ mice. Oligonol treatment more effectively attenuated hepatic CML compared with CEL, at least in part, because CML formation is linked with lipid peroxidation and peroxynitrite production induced by iNOS activity ${ }^{(30)}$

Diabetes is characterised by hyperglycaemia together with biochemical alterations of glucose and lipid metabolism, which is due to impaired carbohydrate utilisation resulting from deficient insulin secretion and/or insulin resistance. In particular, insulin resistance elevates the hepatic output of TAG-rich particles and adipose release of NEFA. When the NEFA supply exceeds utilisation, non-adipose tissues start accumulating TAG, which is aggravated by the simultaneous presence of hyperglycaemia. In the present study, $d b / d b$ mice represented obesity-induced diabetes, along with hyperglycaemia and hyperlipidaemia. The administration of oligonol for 8 weeks to $d b / d b$ mouse groups led to a significant decrease in the serum lipid profile, such as TAG, total cholesterol and NEFA levels, without changes in serum glucose (Table 1). These results indicate that oligonol can ameliorate diabetic pathological conditions related to abnormal lipid metabolism in type 2 diabetes.

Hyperglycaemia and abnormalities in serum lipids can contribute to diverse lipid metabolic changes occurring in the liver, which are strongly associated with the progression of diabetic liver disease. Obesity-induced insulin resistance, which is a typical characteristic of type 2 diabetes, leads to reduced hepatic fatty acid oxidation and increased de novo lipogenesis, and, consequently, excess fat accumulation in the liver ${ }^{(31)}$. Consistent with the results for serum lipids, the oligonol-administered group showed a significant reduction in hepatic TAG and total cholesterol contents compared with the vehicle group (Fig. 4). Next, we analysed the effect of oligonol on hepatic mRNA levels of lipid-synthesising enzymes such as ACC, FAS and HMGR. ACC is an important rate-controlling enzyme involved in the synthesis of malonylCoA, which is both a critical precursor for the biosynthesis of fatty acids and a potent inhibitor of mitochondrial fatty acid oxidation. The phosphorylation and inhibition of ACC by AMP-activated protein kinase led to a fall in the malonyl-CoA content and a subsequent decrease in TAG synthesis, concomitant with an increase in $\beta$-oxidation ${ }^{(32)}$. In the present study, oligonol markedly lowered the mRNA expression of hepatic ACC and FAS, a key enzyme that catalyses the synthesis of saturated long-chain fatty acids, compared with control $d b / d b$ mice. Also, mRNA expression of HMGR, a key enzyme in cholesterol synthesis, was significantly down-regulated by oligonol treatment. It was confirmed that oligonol inhibited hepatic lipid synthesis and accumulation via the suppression of lipogenic enzyme activity.

Lipid metabolism is regulated by several nuclear transcription factors such as SREBP. In the present study, hepatic SREBP-1 in $d b / d b$ mice was significantly down-regulated by the administration of oligonol. However, oligonol administration led to no significant alteration of PPAR $\alpha$ and SREBP-2. These findings were related to the inhibition of hepatic TAG and cholesterol accumulation. HMGR is the main target gene regulated by SREBP-2 and also by SREBP-1, and, therefore, up-regulated SREBP-1 is related to cholesterol synthesis ${ }^{(33,34)}$. This may explain why the reduced hepatic cholesterol content caused by oligonol treatment was mediated by the down-regulation of SREBP-1 without any change in SREBP-2 expression.

In summary, the present results show that oligonol ameliorated oxidative stress and dyslipidaemia in a type 2 diabetic $d b / d b$ mouse model. Oligonol administration inhibited oxidative stress and inflammation through the reduction of ROS generation, lipid peroxidation, and, in turn, the downregulation of $\mathrm{NF}-\mathrm{kB}$ and iNOS protein. Furthermore, the 8 -week administration of oligonol prevented dyslipidaemia 
compared with the vehicle group, which, in turn, reduced the expression of SREBP-1 protein and its target genes ACC, FAS and HMGR, leading to the low-level hepatic lipid deposition of TAG and cholesterol. Consistent with another report ${ }^{(35)}$, the body weight, food intake and water intake of $d b / d b$ mice in our present study were markedly higher than those of $\mathrm{m} / \mathrm{m}$ mice due to augmented food consumption in the former. However, the administration of oligonol for 8 weeks led to no difference in these items. There was no hypoglycaemic effect of oligonol administration in $d b / d b$ mice. Accordingly, the present study suggests that the anti-diabetic effects of oligonol are associated with ameliorations of oxidative stress and abnormal lipid metabolism in type 2 diabetes.

\section{Acknowledgements}

The present study was supported in part by a grant-in-aid (C) from the Ministry of Education, Culture, Sports, Science, and Technology, Japan (no. 19500661 to T. Y.).

T. Y. designed the experiment and wrote the manuscript. All the authors read, commented on and approved the submitted version.

The authors declare that there are no conflicts of interest.

\section{References}

1. Hotamisligil GS (2006) Inflammation and metabolic disorders. Nature 444, 860-867.

2. Ahmed N (2005) Advanced glycation endproducts - role in pathology of diabetic complications. Diabetes Res Clin Practice 67, 3-21.

3. Goh SY \& Cooper ME (2008) The role of advanced glycation end products in progression and complications of diabetes. J Clin Endocrinol Metab 93, 1143-1152.

4. Delarue J \& Magnan C (2007) Free fatty acids and insulin resistance. Curr Opin Clin Nutr Metab Care 10, 142-148.

5. Browning JD \& Horton JD (2004) Molecular mediators of hepatic steatosis and liver injury. J Clin Invest 114, 147-152.

6. Jones PJ \& Varady KA (2008) Are functional foods redefining nutritional requirements? Appl Physiol Nutr Metab 33, $118-123$.

7. Tanaka T, Yoshitake N, Zhao P, et al. (2007) Production of oligomeric proanthocyanidins by fragmentation of polymers. Jpn J Food Chem 14, 134-139.

8. Fujii H, Nishioka H, Wakame K, et al. (2008) Acute, subchronic and genotoxicity studies conducted with oligonol, an oligomerized polyphenol formulated from lychee and green tea extracts. Food Chem Toxicol 46, 3553-3562.

9. Jo EH, Lee SJ, Ahn NS, et al. (2007) Induction of apoptosis in MCF-7 and MDA-MB-231 breast cancer cells by oligonol is mediated by Bcl-2 family regulation and MEK/ERK signaling. Eur J Cancer Prev 16, 342-347.

10. Kundu JK, Chang EJ, Fujii H, et al. (2008) Oligonol inhibits UVB-induced COX-2 expression in HR-1 hairless mouse skin - AP-1 and C/EBP as potential upstream targets. Photochem Photobiol 84, 399-406.

11. Zhang XH, Yokoo H, Nishioka H, et al. (2010) Beneficial effect of the oligomerized polyphenol oligonol on high glucose-induced changes in eNOS phosphorylation and dephosphorylation in endothelial cells. $\mathrm{Br} J$ Pharmacol 159, 928-938.
12. Sakurai T, Nishioka H, Fujii H, et al. (2008) Antioxidative effects of a new lychee fruit-derived polyphenol mixture, oligonol, converted into a low-molecular form in adipocytes. Biosci Biotechnol Biochem 72, 463-476.

13. Ogasawara J, Kitadate K, Nishioka H, et al. (2009) Oligonol, a new lychee fruit-derived low-molecular form of polyphenol, enhances lipolysis in primary rat adipocytes through activation of the ERK1/2 pathway. Phytother Res 23, 1626-1633.

14. Mittal A, Elmets CA \& Katiyar SK (2003) Dietary feeding of proanthocyanidins from grape seeds prevents photocarcinogenesis in SKH-1 hairless mice: relationship to decreased fat and lipid peroxidation. Carcinogenesis $\mathbf{2 4}$, $1379-1388$.

15. Ali SF, LeBel CP \& Bondy SC (1992) Reactive oxygen species formation as a biomarker of methylmercury and trimethyltin neurotoxicity. Neurotoxicology 13, 637-648.

16. Naito C \& Yamanaka T (1978) Lipid peroxides in atherosclerotic diseases. Nippon Ronen Igakkai Zasshi 15, $187-191$.

17. Folch J, Lees M \& Sloane Stanley GH (1957) A simple method for the isolation and purification of total lipides from animal tissues. J Biol Chem 226, 497-509.

18. Mihara M \& Uchiyama M (1978) Determination of malonaldehyde precursor in tissues by thiobarbituric acid test. Anal Biochem 86, 271-278.

19. Hissin PJ \& Hilf R (1976) A fluorometric method for determination of oxidized and reduced glutathione in tissues. Anal Biochem 74, 214-226.

20. Itzhaki RF \& Gill DM (1964) A micro-biuret method for estimating proteins. Anal Biochem 9, 401-410.

21. Brownlee M (2001) Biochemistry and molecular cell biology of diabetic complications. Nature 414, 813-820.

22. Rösen P, Nawroth PP, King G, et al. (2001) The role of oxidative stress in the onset and progression of diabetes and its complications: a summary of a Congress Series sponsored by UNESCO-MCBN, the American Diabetes Association and the German Diabetes Society. Diabetes Metab Res Rev 17, 189-212.

23. Newsholme P, Haber EP, Hirabara SM, et al. (2007) Diabetes associated cell stress and dysfunction: role of mitochondrial and non-mitochondrial ROS production and activity. $J$ Physiol 583, 9-24.

24. Higdon JV \& Frei B (2003) Tea catechins and polyphenols: health effects, metabolism, and antioxidant functions. Crit Rev Food Sci Nutr 43, 89-143.

25. Perron NR \& Brumaghim JL (2009) A review of the antioxidant mechanisms of polyphenol compounds related to iron binding. Cell Biochem Biophys 53, 75-100.

26. Surh YJ, Chun KS, Cha HH, et al. (2001) Molecular mechanisms underlying chemopreventive activities of antiinflammatory phytochemicals: down-regulation of COX-2 and iNOS through suppression of NF-кB activation. Mutat Res 480-481, 243-268.

27. Vander Jagt DL, Hassebrook RK, Hunsaker LA, et al. (2001) Metabolism of the 2-oxoaldehyde methylglyoxal by aldose reductase and by glyoxalase-I: roles for glutathione in both enzymes and implications for diabetic complications. Chem Biol Interact 130-132, 549-562.

28. Yeh CH, Sturgis L, Haidacher J, et al. (2001) Requirement for p38 and p44/p42 mitogen-activated protein kinases in RAGE-mediated nuclear factor- $\mathrm{kB}$ transcriptional activation and cytokine secretion. Diabetes 50, 1495-1504.

29. Lohwasser C, Neureiter D, Popov Y, et al. (2009) Role of the receptor for advanced glycation end products in hepatic fibrosis. World J Gastroenterol 15, 5789-5798. 
30. Nagai R, Unno Y, Hayashi MC, et al. (2002) Peroxynitrite induces formation of $N^{\varepsilon}$-(carboxymethyl)lysine by the cleavage of Amadori product and generation of glucosone and glyoxal from glucose: novel pathways for protein modification by peroxynitrite. Diabetes 51, 2833-2839.

31. Kahn SE, Hull RL \& Utzschneider KM (2006) Mechanisms linking obesity to insulin resistance and type 2 diabetes. Nature 444, 840-846.

32. Velasco G, Geelen MJ \& Guzmán M (1997) Control of hepatic fatty acid oxidation by 5 -AMP-activated protein kinase involves a malonyl-CoA-dependent and a malonyl-CoAindependent mechanism. Arch Biochem Biophys 337, $169-175$
33. Bennett MK, Seo YK, Datta S, et al. (2008) Selective binding of sterol regulatory element-binding protein isoforms and co-regulatory proteins to promoters for lipid metabolic genes in liver. J Biol Chem 283, 15628-15637.

34. Kaplan M, Kerry R, Aviram M, et al. (2008) High glucose concentration increases macrophage cholesterol biosynthesis in diabetes through activation of the sterol regulatory element binding protein 1 (SREBP1): inhibitory effect of insulin. I Cardiovasc Pharmacol 52, 324-332.

35. Lee YA, Cho EJ \& Yokozawa T (2008) Effects of proanthocyanidin preparations on hyperlipidemia and other biomarkers in mouse model of type 2 diabetes. J Agric Food Chem $\mathbf{5 6}$, $7781-7789$. 